\title{
EFEITO DA CITOCININA 6-BENZILAMINOPURINA (BAP) SOBRE O ESTABELECIMENTO IN VITRO DE SEGMENTOS NODAIS DE Rosa sp.
}

\author{
Jéssica Paloma Gama dos Santos Silva1; Tanara Pletsch Dalla Costa²; Milla Karolina Correa Costa ${ }^{3}$; Maria \\ Rayra Silva de Araújo ; Kaylanny Silva Araújo5; Ana Caroline Miléo da Silva6; Patrícia Chaves de Oliveira7; \\ Eliandra de Freitas Sia 8 . \\ 1Universidade Federal do Oeste do Pará (UFOPA), Santarém, Pará, Brasil, jessicapalloma@yahoo.com.br \\ 2UFOPA, Santarém, Pará, Brasil, tanara_dallacosta@hotmail.com \\ 3Bacharelado em Biotecnologia, IBEF, UFOPA, Santarém, Pará, Brasil, m.karolina@hotmail.com \\ 4UFOPA, Santarém, Pará, Brasil, rayraraujo@hotmail.com \\ 5UFOPA, Santarém, Pará, Brasil, kaylannyaraujo@gmail.com \\ 6UFOPA, Santarém, Pará, Brasil, carolmileo@live.com \\ 7UFOPA, Santarém, Pará, Brasil, lab.estudosamazonicos@gmail.com \\ 8UFOPA, Santarém, Pará, Brasil, eliandra.sia@hotmail.com
}

RESUMO: As rosas são consideradas uma das plantas ornamentais mais importantes do mercado floricultor. Tendo isto em vista, empregar novas tecnologias produtivas para esta cultura é de grande importância científica e econômica. Por isto, o objetivo neste trabalho foi avaliar o efeito de diferentes concentrações da citocinina 6-benzilaminopurina (BAP) sobre a indução de brotos em Rosa sp. in vitro. Segmentos nodais contendo gemas axilares de uma matriz comercial de Rosa sp. foram suplementados com diversas concentrações de $\operatorname{BAP}(0,0 ; 0,25 ; 0,5 ; 1,0 ; 1,5 \mathrm{mg} / \mathrm{L})$. As maiores taxas de explantes responsivos (que apresentaram brotações) foram obtidas nas maiores concentraç̃̃es do hormônio BAP, embora não haja diferença estatística significativa a nível de 5\% entre os tratamentos. Portanto a variação da concentração de BAP influenciou no número de explantes estabelecidos in vitro, proporcionando maior sobrevivência e brotações nos segmentos nodais de Rosa sp.

PALAVRAS-CHAVE: Cultura de tecidos, Micropropagação, Rosa.

\section{EFFECT OF CYTOKININ 6-BENZYLAMINOPURINE (BAP) ON THE IN VITRO ESTABLISHMENT OF NODAL SEGMENTS OF Rosa sp.}

ABSTRACT: Roses are considered one of the most important ornamental plants in the flower market. With this in mind, employing new productive technologies for this culture is of great scientific and economic importance. Therefore, the objective of this work was to evaluate the effect of different concentrations of BAP cytokinin on the induction of shoots in Rosa sp. in vitro. Nodal segments containing axillary buds of a commercial matrix of Rosa sp. were supplemented with various concentrations of BAP $(0.0,0.25,0.5,1.0,1.5 \mathrm{mg} / \mathrm{L})$. The highest rates of responsive explants (which had buds) were obtained at the highest concentrations of BAP hormone, although there was no significant statistical difference at 5\% between treatments. Therefore, the variation of the BAP concentration influenced the number of 
explants established in vitro, providing greater survival and sprouting in the nodal segments of Rosa sp.

KEYWORDS: Micropropagation, Rose, Tissue culture.

\section{EFECTO DE LA CITOCININA 6-BENZILAMINOPURINA (BAP) SOBRE EL ESTABLECIMIENTO IN VITRO DE SEGMENTOS NODALES DE Rosa sp.}

RESUMEN: Las rosas son consideradas una de las plantas ornamentales más importantes del mercado floricultor. Teniendo esto en cuenta, emplear nuevas tecnologías productivas para esta cultura es de gran importancia científica y económica. Por eso, el objetivo en este trabajo fue evaluar el efecto de diferentes concentraciones de la citocina BAP sobre la inducción de brotes en Rosa sp. in vitro. Segmentos nodales que contienen gemas axilares de una matriz comercial de Rosa sp. se han suplementado con diversas concentraciones de $\operatorname{BAP}(0,0,0,25,0,5,1,0,1,5 \mathrm{mg} / \mathrm{L})$. Las mayores tasas de explantes responsivos (que presentaron brotes) se obtuvieron en las mayores concentraciones de la hormona BAP, aunque no hubo diferencia estadística significativa en el 5\% entre los tratamientos. Por lo tanto la variación de la concentración de BAP influenció en el número de explantes establecidos in vitro, proporcionando mayor supervivencia y brotaciones en los segmentos nodales de Rosa sp.

PALABRAS CLAVE: Cultivo de tejidos, Micropropagación, Rosa.

A família Rosaceae agrupa vários gêneros com características morfológicas altamente diversas, ampla distribuição geográfica e grande importância econômica devido a utilização de seus frutos, como maçã, pera, pêssego, ameixa etc., e das suas flores, como é o caso das plantas do gênero Rosa (HUMMER; JANICK, 2009). Este é um dos mais economicamente importantes gêneros da floricultura mundial, sendo que algumas espécies são utilizadas também na produção de óleo essencial para a perfumaria, culinária e como planta medicinal pelo conhecimento tradicional (BOSKABADY et al., 2011) e indústria farmacêutica (PRATA et al., 2017).

As rosas são as mais importantes flores para corte distribuídas no Brasil (SEBRAE, 2015; DIAS et al., 2016), porém, o país possui grande deficiência em pesquisas para aprimorar o manejo desta cultura e para programas de melhoramento visando a obtenção de novas variedades 
resistentes a doenças, com características morfológicas comercialmente interessantes e adaptadas às condições edafoclimáticas das diferentes regiões do país (RESENDE; TOLEDO, 2014; OLIVEIRA et al., 2016; CAVALCANTE JÚNIOR et al., 2017) . Tendo em vista tal problemática, a micropropagação surge como uma boa alternativa para o cultivo de rosas no Brasil.

Na micropropagação, as plantas são cultivadas in vitro com meios nutritivos adequados e sob condições controladas de temperatura, luminosidade e fotoperíodo. Essa técnica, que viabiliza a produção de um elevado número de mudas idênticas à planta matriz e com qualidade fitossanitária, evidencia, portanto, uma grande vantagem comparativa sobre a propagação vegetativa tradicional (ALMEIDA et al., 2015).

O crescimento de plantas in vitro exige a adição ao meio de cultura de reguladores de crescimento. A indução de brotações in vitro ocorre pelo desequilíbrio hormonal induzido por concentração adequada e balanceada de reguladores vegetais adicionadas ao meio
(MONFORT et al., 2012). Os principais tipos de reguladores, com efeito sobre a micropropagação, são as citocininas e auxinas, as quais atuam no crescimento e desenvolvimento do explante (BIELACH et al., 2012).

Essas substâncias são essenciais para o desenvolvimento dos explantes e estão intimamente relacionadas com a divisão celular e o crescimento do meristema (REIS et al., 2008). As citocininas, a exemplo do BAP (6-benzilaminopurina), agem induzindo a quebra da dominância apical e proliferação de gemas axilares, promovendo o desenvolvimento da parte aérea. O BAP é a citocinina disponível comercialmente que apresenta os melhores resultados na micropropagação (MOURA et al., 2012). Portanto o objetivo neste trabalho foi avaliar o efeito da citocinina 6-benzilaminopurina (BAP) sobre o estabelecimento in vitro de segmentos nodais de Rosa sp.

Os ensaios foram realizados no Laboratório de Estudo dos Ecossistemas Amazônicos (LEEA), da Universidade Federal do Oeste do Pará (UFOPA). Foram utilizados como explantes segmentos nodais contendo gemas axilares sadias de 
uma planta matriz de Rosa, cortados com o auxílio de uma lâmina de bisturi e lavados abundantemente com água corrente e detergente neutro. Posteriormente, em capela de fluxo laminar, os segmentos nodais foram imersos em álcool 70\% durante 5 minutos, em hipoclorito de sódio 50\% durante 30 minutos, e enxaguadas em água destilada e autoclavada três vezes consecutivas. Após esse procedimento, segmentos nodais medindo aproximadamente $2 \mathrm{~cm}$ foram inoculados em frascos contendo 10 $\mathrm{mL}$ de meio de cultura MS (MURASHIGE; SKOOG, 1962), suplementado com sacarose $(30 \mathrm{~g} / \mathrm{L})$, ágar (7g/L), 0,1 mg/L de ácido indolil-3-acético (AIA) e 5 concentrações diferentes de BAP (mg/L): 0,$0 ; 0,25 ; 0,5 ; 1,0 ; 1,5 . \mathrm{pH}$ foi ajustado para $5,7 \pm 0,1$.

O delineamento experimental utilizado foi o inteiramente casualizado em uma fatorial $5 \times 5$ com 5 tratamentos e 5 repetições, sendo cada repetição composta por 5 unidades experimentais (tubos contendo um explante). Os frascos inoculados foram mantidos em sala de crescimento iluminadas com lâmpadas fluorescentes brancas frias que fornecem uma densidade de fluxo de fótons 30 $\mu \mathrm{mol} / \mathrm{m} 2 / \mathrm{s}$, fotoperíodo de 16 horas e temperatura de $27^{\circ} \mathrm{C}$. Foram realizadas 4 avaliações: 7; 14; 21 e 30 dias após o cultivo, quando foram observadas as seguintes variáveis: número de explantes responsivos, isto é, que formaram brotos, além de explantes que apresentaram, oxidação (necrose) e contaminação. No final do $30^{\circ}$ dia de cultivo, foi avaliado o índice de sobrevivência que é calculado pelo número de explantes responsivos somados aos que não foram responsivos e ambos sem contaminação ou necrose.

Os resultados das variáveis explantes responsivos, explantes oxidados, explantes contaminados e índice de sobrevivência foram submetidos à Análise de Variância utilizando o software estatístico BioEstat 5.0 (AYRES et al., 2007). Houve uma tendência de decrescimento em relação à contaminação dos explantes no decorrer do tempo. O mesmo foi observado por Sousa et al. (2009), utilizando sementes de Cattleya walkeriana e Shomburgkia crispa onde o período crítico para contaminação e oxidação dos explantes introduzidos in vitro ocorreram nos primeiros 30 dias de 
cultivo. Neste trabalho os resultados mostram que a fase crítica ocorreu nos primeiros 14 dias, após esse período, o índice de contaminação diminuiu (Figura $1)$.

O índice de contaminação depende da idade e do tipo do explante, da concentração da solução esterilizante e do tempo de exposição do explante à solução, fazendo-se necessário a adaptação de protocolo à cada cultura (FERREIRA et al., 2009). Além disso, explantes extraídos de plantas matrizes oriundas do campo tendem a apresentar maiores níveis de contaminação (SANTOS et al., 2015).

Figura 1. Porcentagem de explantes contaminados nos 5 tratamentos (concentrações diferentes de BAP) nas quatro avaliações (1: 7 dias; 2: 14 dias; 3: 21 dias; 4: 30 dias).

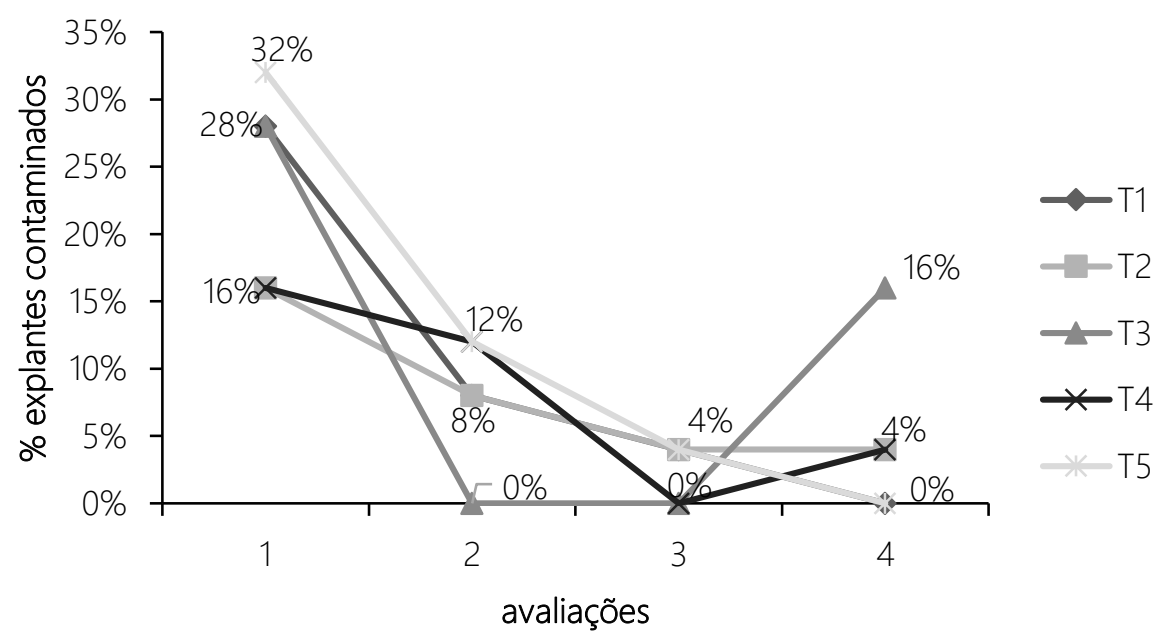

Tabela 1. Análise de variância dos parâmetros analisados ao término de 30 dias de estabelecimento de explantes de Rosa sp. in vitro nas 5 concentrações diferentes da citocinina BAP. (*: significativo a 5\% de probabilidade ( $p<0,05)$; ns: não significativo).

\begin{tabular}{ccccc}
\hline & \multicolumn{4}{c}{ Quadrados Médios } \\
\cline { 2 - 5 } Fonte de Variação & $\begin{array}{c}\text { Explantes } \\
\text { responsivos }\end{array}$ & $\begin{array}{c}\text { Explantes } \\
\text { contaminados }\end{array}$ & $\begin{array}{c}\text { Explantes } \\
\text { necrosados }\end{array}$ & $\begin{array}{c}\text { Índice de } \\
\text { sobrevivência }\end{array}$ \\
\hline BAP & $3,16^{\text {ns }}$ & $0,5^{\text {ns }}$ & $2,64^{*}$ & $3,44^{\text {ns }}$ \\
CV\% & $46,22 \%$ & $18,25 \%$ & $95,61 \%$ & $37,03 \%$ \\
\hline
\end{tabular}


Em relação à indução de brotações, não houve diferença estatística significativa entre os diferentes tratamentos (Figura 2). Porém na terceira avaliação, após 21 dias de cultivo, percebeu-se uma maior tendência na ocorrência de brotações para todos os tratamentos que continham o regulador, o qual se manteve aos 30 dias de estabelecimento. Baig et al. (2011) observaram a brotação máxima em cultivares de rosa na presença de $1,0 \mathrm{mg}$ $\mathrm{L}^{-1}$ de BAP ao meio de cultura. Por sua vez, Senapati e Rout (2008) obtiveram maior número de brotações em diferentes cultivares de Rosa hybrida L. utilizando o BAP em concentrações de 1,5 e 2,0 mg L 1 em explantes de seguimentos nodais. Segundo Aragão et al. (2011), este tipo de explante é o mais indicado para a indução de brotações usando o BAP.

Figura 2. Porcentagem de explantes responsivos (apresentaram brotações) nos 5 tratamentos (concentrações diferentes de BAP) nas 4 avaliações (1: 7 dias; 2: 14 dias; 3: 21 dias; 4: 30 dias).

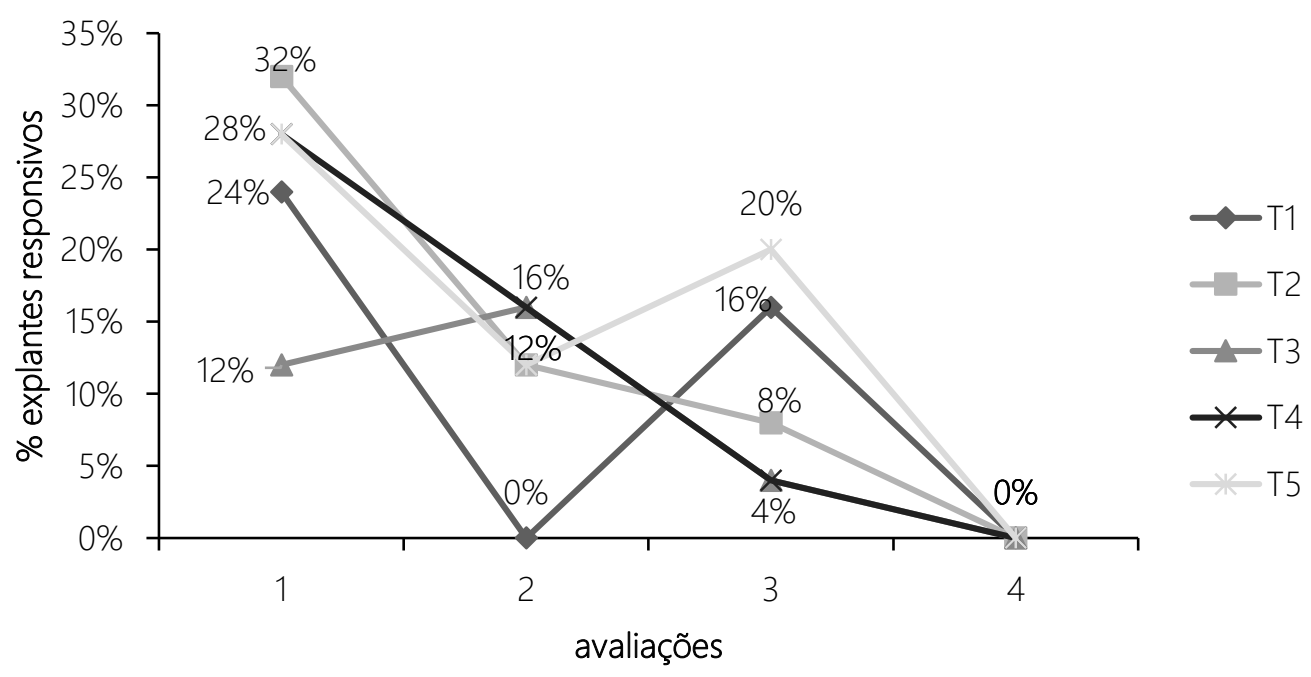

Kumud et al. (2015) em um trabalho estudando a micropropagação em diferentes cultivares de Rosa sp, com o uso da citocinina cinetina, demostraram que esse regulador, semelhante ao BAP, induziu satisfatoriamente brotações para as diferentes cultivares testadas, com índice de 46\% de brotações.

Na figura 3, observa-se que houve diferença significativa a nível de 5\% de 
probabilidade na porcentagem de explantes necrosados. No qual, os tratamentos T1 e T3 apresentaram a maior quantidade de explantes oxidados, possivelmente por fatores inerentes aos explantes. Os explantes T4 obtiveram taxas baixas de necrose e T5 não apresentaram necrose.

Figura 3. Porcentagem de explantes necrosados (oxidados) nos 5 tratamentos (concentrações diferentes de BAP) nas 4 avaliações (1: 7 dias; 2: 14 dias; 3: 21 dias; 4: 30 dias).

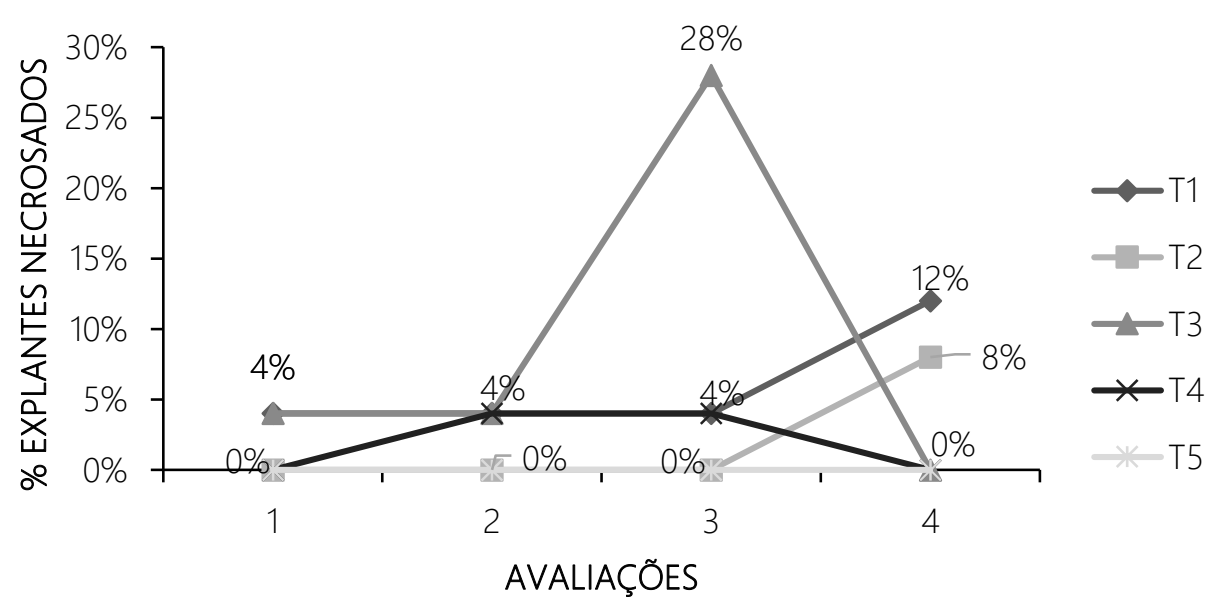

No trabalho de Drefahl (2004), foram utilizados segmentos nodais de Rosa $x$ hybrida obtidos de uma planta matriz de campo, no qual a assepsia foi realizada com etanol e $\mathrm{NaClO}$ a diferentes concentrações, melhores resultados forma obtidos quando se utilizou etanol 70\% por 1 min e $\mathrm{NaClO}$ 2\% por 5 min, relacionando com os índices de necrose dos segmentos nodais. Por isso, se faz importante o ajuste dos protocolos de desinfestação para cada espécie a ser trabalhada, de forma a reduzir os índices de contaminação, sem afetar no desenvolvimento de brotos e na morte do tecido.

De acordo com o trabalho de Pelizza et al. (2013), no qual foi realizado o estabelecimento in vitro de diferentes cultivares de mirtileiro, a oxidação dos explantes foi influenciada tanto pelo processo de desinfestação quanto pelo cultivar, apresentando um índice de oxidação de até 16,69\%. 
Figura 4. Comparação dos parâmetros explantes contaminados, responsivos e necrosados com o Índice de sobrevivência dos explantes de Rosa sp. nos 5 tratamentos (concentrações diferentes de BAP) ao final das 4 avaliações.

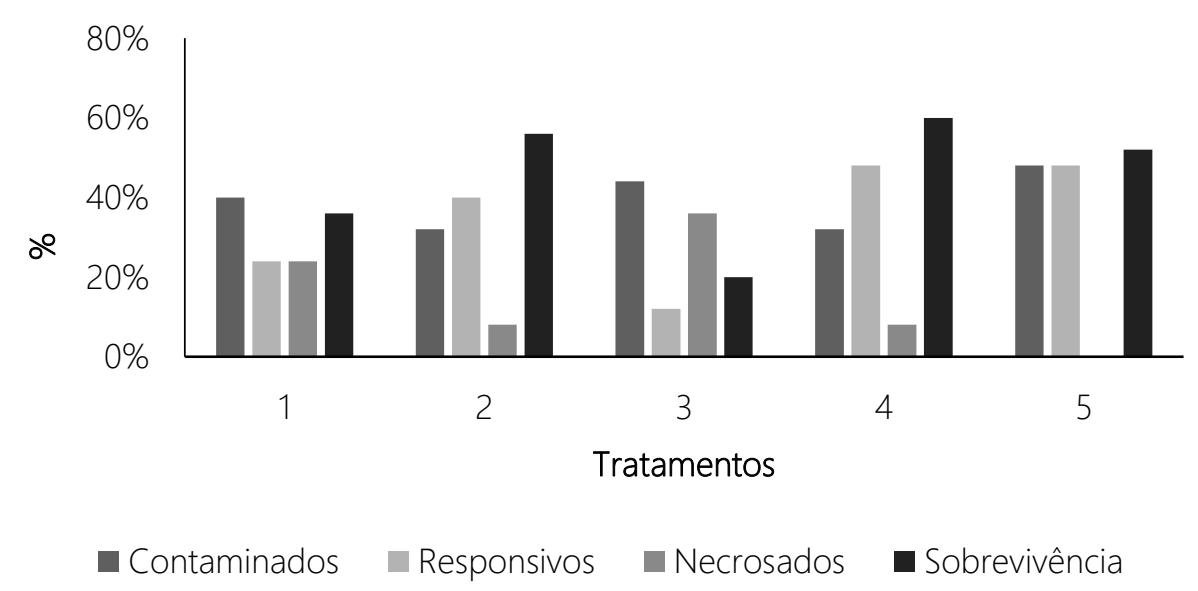

Na figura 4, encontra-se a taxa de necrosados e menor índice de explantes sobrevivência dos explantes contaminados. No trabalho de Oliveira et desenvolvidos, em comparação aos índices de explantes contaminados, responsivos e necrosados, nos cinco tratamentos realizados. Nos presentes tratamentos, houve uma alta taxa de sobrevivência na presença do hormônio BAP, com exceção do tratamento 3 no qual houve alta taxa de necrose.

Não houve diferença estatística significativa entre os tratamentos ( $p>0,05)$, apenas entre os parâmetros analisados $(p=0,0530)$, porém pode-se observar que os tratamentos T4 e T5 apresentaram altos índices de sobrevivência, baixos níveis de explantes al. (2008), com diferentes cultivares de amoreira-preta, foi obtida uma baixa taxa de estabelecimento dos explantes, em média 41\%, a qual estava relacionada com a origem do material de propagação, oriunda do campo.

Morais et al. (2014), avaliando o efeito de reguladores de crescimento vegetal no cultivo in vitro de hortelã-pimenta (Mentha x Piperita L), observou que o aumento da concentração de BAP influenciava positivamente a sobrevivência dos explantes, enquanto Oliveira et al. (2016), avaliando o efeito de BAP e ácido naftaleno acético (ANA) 
sobre a propagação in vitro de mangabeira (Hancornia speciosa Gomes) obteve maiores índices de sobrevivência na ausência de BAP. Este favorecimento da sobrevivência, no caso da Rosa sp. e de hortelã-pimenta, pode estar relacionado ao efeito que as citocininas possuem de retardar os efeitos fisiológicos degenerativos, ou seja, impedem o envelhecimento dos tecidos vegetais (TAIZ; ZEIGER, 2004).

A variação da concentração de BAP influenciou no número de explantes estabelecidos in vitro, no qual as concentrações de 1,0 a $1,5 \mathrm{mg} \mathrm{L}^{-1}$ proporcionaram maior sobrevivência e brotações nos segmentos nodais.

Em concentrações maiores da citocinina os índices de necrose foram significativamente menores, podendo indicar um efeito retardador da senescência em tecidos vegetais.

\section{AGRADECIMENTOS}

Ao Laboratório de Estudo dos Ecossistemas Amazônicos (LEEA) e à Universidade Federal do Oeste do Pará (UFOPA).

\section{REFERÊNCIAS}

ALMEIDA, N. M. de; PACHECO JUNIOR, R. G.; CÉZAR, J. de O.; GONÇALVES, H. A.; SOUZA, A. da S. Produção de mudas micropropagadas de mandioca (Manihot esculenta (rantz) em larga escala: uma inovação tecnológica. In: CONGRESSO BRASILEIRO DE MANDIOCA, 16; CONGRESSO LATINO-AMERICANO E CARIBENHO DE MANDIOCA, FOZ do Iguaçu. Anais... Foz do Iguaçu: SBM, 2015. CD-ROM.

AYRES, M.; AYRES JUNIOR, M.; AYRES, D. L. SANTOS, A. S. dos; AYRES, L. L. Bioestat Versão 5.0. Sociedade Civil Mamirauá, MCT-CNPq, Belém, Pará, Brasil, 2007.

ARAGÃO, A. K. O.; ALOUFA, M. A. I.; COSTA, I. A. Effect of bap (6benzylaminopurine) on shoot induction in explants of brazilwood. Cerne, v. 17, n. 3, p. 339-345, 2011.

BAIG, M. M. Q.; HAFIZ, I. A.; HUSSAIN, A.; AHMAD, T.; ABBASI, N. A. An efficient protocol for in vitro propagation of Rosa gruss an teplitz and Rosa centifolia. African Journal of Biotechnology, v. 10, p. 4564-4573, 2011.

BIELACH, A.; DUCLERCQ, J.; MARHAVÝ, P.; BENKOVÁ, E. Genetic approach towards the identification of auxincytokinin crosstalk components involved in root development. Philosophical Transactions of the Royal Society of London, v. 367, n. 1595, p. 1469-78, 2012.

BOSKABADY, M. H., SHAFEl, M. N., SABERI, Z., \& AMINI, S. Pharmacological effects of Rosa damascena. Iranian Journal of Basic Medical Sciences, v. 14, n. 4, p. 295-307, 2011. 
CAVALCANTE JÚNIOR, J. A.; AZEVEDO, B. M. de; SOUSA, G. G. de; VASCONCELOS, D. $V$; ARAÚJO VIANA, T. V. de; REBOUÇAS NETO, M. de O. Manejo da irrigação na cultura da roseira em ambiente protegido. Revista Brasileira De Agricultura Irrigada, v. 7, n. 4, p. 269-276, 2013.

DIAS, G. M.; SIGRIST, J. M. M.; CIA, P.; HONÓRIO, S. L. Wet and dry storage of cut roses. Ornamental Horticulture, v. 22, n. 2, p. 166-171, 2016.

DREFAHL, A. Organogênese de rosa $x$ hybrida cv. vegas, Curitiba, 2004. 88 f. Tese (Mestrado em Ciências Agrárias) Departamento de Fitotecnia e Fitossanitarismo, Setor de Ciências Agrárias, Universidade Federal do Paraná, Curitiba, 2004.

FERREIRA, M. das G. R.; SANTOS, M. R. A. dos; BRAGADO, A. C. R. Propagação in vitro de cupuaçuzeiro: desinfestação de explantes florais. Saber Científico, Porto Velho, v. 2, n. 2, p. 37-44, 2009.

HUMMER, KIM E.; JANICK, JULES. Rosaceae: taxonomy, economic importance, genomics. In: FOLTA, K. M.; GARDINER, S. E. (Org.) Genetics and genomics of Rosaceae. New York: Springer, 2009, p. 1-17.

KUMUD, S.; HEM, P.; VIJAY, R. Micropropagation of rose cultivars: Biotechnological application to floriculture. Journal of Environmental Research and Development, v. 10, n. 1, p. 40, 2015.

MONFORT, L. E. F; PINTO, J. E. B. P.; BERTOLUCCI, S. K. V.; ROSSI, Z. T. T.; SANTOS, F. M. Efeito do BAP no cultivo in vitro de Ocimum selloi Benth. Revista Brasileira de Plantas Medicinais, v. 14, n. 3, p. 458-463, 2012.

MORAIS, T. P.; ASMAR, S. A.; LUZ, J. M. Q. Reguladores de crescimento vegetal no cultivo in vitro de Mentha $x$ Piperita L. Revista Brasileira de plantas medicinais, v. 16, n. 2, p. 350-355, 2014.

MOURA, L. C.; TITON, M.; FERNANDES, J. S. C.; SANTANA, R. C.; OLIVEIRA, M. L. R. Micropropagação de Sucupira-preta por meio de gemas axilares. Pesquisa

Agropecuária Brasileira, Brasília, v. 47, n. 12, p. 1691-1698, 2012.

MURASHIGE, T.; SKOOG, F. A revised medium for rapid growth and bio assays with tobacco tissue cultures. Physiologia plantarum, v. 15, n. 3, p. 473-497, 1962.

OLIVEIRA, R. P.; NINO, A. F. P.; FERREIRA, L. V. Potencial de multiplicação in vitro de cultivares de amoreira-preta. Revista Brasileira de Fruticultura, v. 30, n. 3, p. 585-589, 2008.

OLIVEIRA, E. C.; ASSUNÇÃO CARVALHO, J. de; ALMEIDA, E. F. A.; REZENDE, F. C.; REIS, S. N.; MIMURA, S. N. Rendimento de rosas cultivadas em ambiente protegido sob diferentes níveis de irrigação. Irriga, v. 21, n. 1, p. 14-24, 2016.

OLIVEIRA, K. S.; FREIRE, F. A. M. de; ALOUFA, M. A. I. Efeito de 6benzilaminopurina e ácido naftalenoacético sobre a propagação in vitro de Hancornia speciosa. Floresta, v. 46, n. 3, p. 335-342, 2016.

PELIZZA, T. R.; SILVEIRA, F. N.; MUNIZ, J.; GRIMALDI, F.; RUFATO, L; KRETZSCHMAR, A. A. Estabelecimento in 
vitro de mirtileiro: cultivares Bluecrop, Duke e Misty. Plant Cell Culture and Micropropagation, Lavras, v.9, n. 1-2, p. 24-29, 2013.

PRATA, G. G. B.; SOUZA, K. O. de; LOPES, M. M. A.; OLIVEIRA, L. S.; ARAGAO, F. A. S.; ALVES, R. E.; SILVA, S. M. Nutritional Characterization, Bioactive Compounds and Antioxidant Activity of Brazilian Roses (Rosa spp). Journal of Agricultural Science and Technology, v. 19, p. 929-941, 2017.

REIS, E. S.; PINTO, J. E. B. P.; ROSADO, L. D. S.; CORRÊA, R. M. Influência do meio de cultura na germinação de sementes in vitro e taxa de multiplicação de Melissa officinalis L. Revista Ceres, v.55, p.160-167, 2008.

RESENDE， W. T.; TOLEDO, M. Especialização regional produtiva em Barbacena (MG) e municípios vizinhos: o cultivo das rosas. Caderno de Geografia, v. 24, n. 1, p. 179-190, 2014.

SANTOS, M. R. A. dos; CHAGAS, S. E. da S.; GUIMARÃES, M. de C. M. Estabelecimento de protocolo para descontaminação de explantes foliares de bacurizeiro (Platonia insignis Mart.). Saber Científico, v. 4, n. 2, p. 15-23, 2015.

SEBRAE. Balanço Comercial da Floricultura Brasileira. Flores e plantas ornamentais do Brasil (série estudos mercadológicos), São Paulo, v. 2, p. 73-77, 2015.

SENAPATI, S. K.; ROUT, G. R. Study of culture conditions for improved micropropagation of hybrid rose. Horticultural Science, v. 35, p. 27-34, 2008.
TAIZ, L.; ZEIGER, E. Fisiologia Vegetal. 3. ed. Porto Alegre: Artmed, 2004. 719 p. 